
for Biofuels

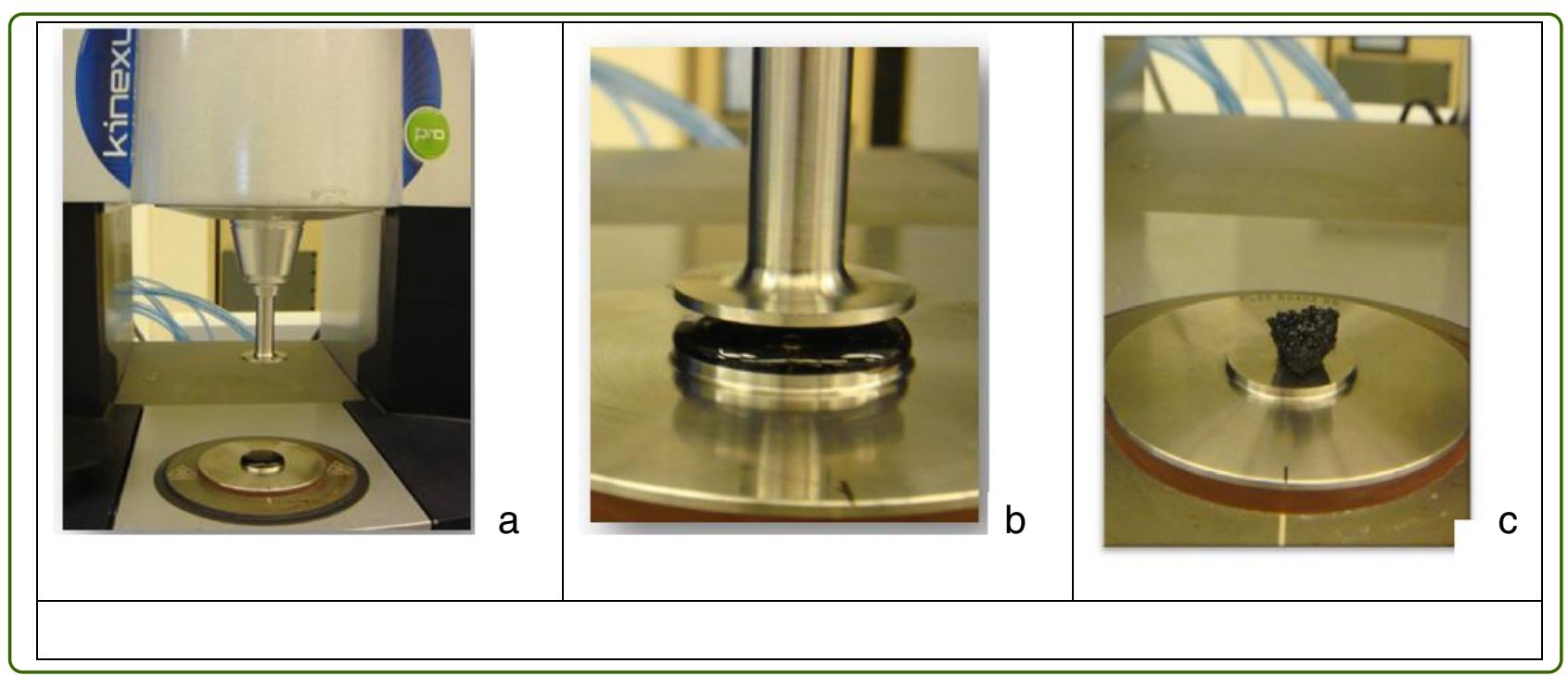

\title{
Impact of high biomass loading on ionic liquid pretreatment
}

Cruz et al. 


\title{
Impact of high biomass loading on ionic liquid pretreatment
}

\author{
Alejandro G Cruz ${ }^{1}$, Chessa Scullin ${ }^{1,2}$, Chen Mu', Gang Cheng ${ }^{1,2,3}$, Vitalie Stavila², Patanjali Varanasi ${ }^{1}$, Dongyan Xu', \\ Jeff Mentel ${ }^{4}$, Yi-De Chuang ${ }^{5}$, Blake A Simmons ${ }^{1,2}$ and Seema Singh ${ }^{1,2^{*}}$
}

\begin{abstract}
Background: Ionic liquid (IL) pretreatment has shown great potential as a novel pretreatment technology with high sugar yields. To improve process economics of pretreatment, higher biomass loading is desirable. The goal of this work is to establish, the impact of high biomass loading of switchgrass on IL pretreatment in terms of viscosity, cellulose crystallinity, chemical composition, saccharification kinetics, and sugar yield.

Results: The pretreated switchgrass/IL slurries show frequency dependent shear thinning behavior. The switchgrass/L slurries show a crossover from viscous behavior at $3 \mathrm{wt} \%$ to elastic behavior at $10 \mathrm{wt} \%$. The relative glucan content of the recovered solid samples is observed to decrease with increasing levels of lignin and hemicelluloses with increased biomass loading. The IL pretreatment led to a transformation of cellulose crystalline structure from I to II for 3, 10, 20 and 30 wt\% samples, while a mostly amorphous structure was found for 40 and 50 wt $\%$ samples.

Conclusions: IL pretreatment effectively reduced the biomass recalcitrance at loadings as high as 50 wt\%. Increased shear viscosity and a transition from 'fluid' like to 'solid' like behavior was observed with increased biomass loading. At high biomass loadings shear stress produced shear thinning behavior and a reduction in viscosity by two orders of magnitude, thereby reducing the complex viscosity to values similar to lower loadings. The rheological properties and sugar yields indicate that 10 to $50 \mathrm{wt} \%$ may be a reasonable and desirable target for IL pretreatment under certain operating conditions.
\end{abstract}

Keywords: Ionic liquid pretreatment, Biofuels, High biomass loading, Rheology, Cellulose crystallinity

\section{Background}

Lignocellulosic biomass consists of a complex matrix of cellulose, hemicelluloses and lignin [1]. Chemical pretreatment is an essential step in the conversion of lignocellulosic to biofuel [2-4], but is generally considered the second most expensive operating cost in the conversion process [5]. One of the most significant methods to decrease the cost of pretreatment is to increase biomass loading and reduce IL use $[5,6]$. In order to determine the optimal pretreatment process conditions, it is necessary to understand the rheological properties as a function of biomass loading and the impact of the higher biomass loading levels on

\footnotetext{
* Correspondence: seesing@sandia.gov

${ }^{1}$ Deconstruction Division, Joint BioEnergy Institute, Lawrence Berkeley

National Laboratory, Berkeley CA, USA

${ }^{2}$ Biological and Materials Science Center, Sandia National Laboratories, Livermore CA, USA

Full list of author information is available at the end of the article
}

process efficiency and subsequent sugar yield [7,8]. Rheological properties of biomass slurries during saccharification and fermentation have been reviewed in the literature [9-12]. Both the particle size and the concentration of insoluble solids in the slurries have been shown to affect rheological properties such as the apparent viscosity and the yield stress $[9,10,13,14]$. Certain pretreatments have been shown to increase the surface area of the biomass and partially, or completely, solubilize the biomass $[2,13,15-18]$. The rheological properties of the pretreated slurries would depend on the type of pretreatment, biomass loading, particle size, the extent of dissolution, and the amount of insoluble solids present $[13,14,19]$. Further increasing the biomass loading during pretreatment impacts the dissolution of biomass and the rheological properties of the slurries produced. For example, the rheological properties such as yield stress and plastic viscosities of dilute acid pretreated spruce slurries have

\section{Biomed Central}


been shown to exhibit a strong dependence on the insoluble solids present in the slurry [14]. Ehrhardt et al. found that both yield stress and plastic viscosities increased with biomass loadings during dilute acid pretreatment [19].

Previous experiments have shown that both chemical composition and physical properties of the pretreated biomass play significant roles in determining saccharification efficiency. Chemical composition of the biomass $[2,20,21]$ and lignin content have been shown to affect saccharification kinetics [16,22-24]. Cellulose morphology in the biomass has also been shown to affect saccharification kinetics [25-30], such as the transformation of cellulose I to mostly amorphous cellulose after pretreatment $[17,18,30]$. IL pretreatment with certain ILs, primarily those with imidazolium cations, has been shown to decrease biomass recalcitrance and increase saccharification efficiency for a wide range of biomass feedstocks $[17,31,32]$. This increase in saccharification efficiency after IL pretreatment has been attributed to a combination of delignification, decreased cellulose crystallinity and increased cellulose accessibility $[15,17,32]$. The majority of the results reported in the literature on IL pretreatment to date have been achieved using relatively low biomass loading levels (3-10 wt\%), with very few reports on the impact of high biomass loading (> $20 \mathrm{wt} \%$ ) [7]. Increasing the biomass loading to $40-50 \mathrm{wt} \%$ during IL pretreatment was shown to have a prominent effect on the overall economics of biorefinery operation in a previous report that is the primary motivation and benchmark for this experimental study [5]. Although the impacts of high biomass loading of corn stover during IL pretreatment have been recently studied by Wu et al. [7], implications of high biomass loading on rheological properties were not established. In addition, different pretreatment conditions on the structure of biomass and its relation with enzymatic hydrolysis need to be explored further at higher loading levels to determine if this is a suitable operating environment for a biorefinery setting. The focus of the current study is to establish, for the first time, the impact of high biomass loading of switchgrass on IL pretreatment in terms of viscosity, cellulose crystallinity, chemical composition, saccharification kinetics, and sugar yields.

\section{Results}

Effect of biomass loading on rheological properties of pretreated slurries

Previous studies have suggested that the viscosity of biomass slurries increases with increased solid loading $[9,10,13,14]$. The rheological properties of the biomass slurries were measured after $\left[\mathrm{C}_{2} \mathrm{mim}\right][\mathrm{OAc}]$ pretreatment at different biomass loadings. The shear viscosity was first measured by cooling the biomass slurry and applying a shear rate of $1 \mathrm{sec}^{-1}$ at $25^{\circ} \mathrm{C}$. As expected, increasing the solids loading of the biomass slurries increased shear viscosity (Figure 1). The shear viscosity increased by 3 orders of magnitude on increasing the biomass loading from 3 to $50 \mathrm{wt} \%$.

Increasing frequency on biomass slurries can result in shear thinning, i.e. the decrease of complex viscosity due to an increase in shear stress rate [9]. To better characterize this effect the elastic (storage G') modulus, viscous (loss G") modulus and complex viscosity $\left(\eta^{\prime \prime}\right)$ were measured using a frequency sweep between $0.01 \mathrm{~Hz}$ to $10 \mathrm{~Hz}$ (Figure 2 and Additional file 1: Figure S2). At a biomass loading of $3 \mathrm{wt} \%$, the elastic modulus is lower than the viscous modulus, indicating that the pretreated slurry acts as a fluid. With increasing the biomass loading to greater than $10 \mathrm{wt} \%$, the viscous modulus increases and is greater than the elastic modulus, indicating solid like behavior. The difference in the elastic modulus and viscous modulus increases monotonically with biomass loading. The complex viscosity of the $3 \mathrm{wt} \%$ loading biomass slurry decreases by at least 20 times on increasing the frequency 100 fold. Interestingly, increasing the loading of the pretreated biomass slurries clearly enhances the shear thinning behavior as can be seen in Figure 2. When the frequency was increased by 100 fold, the complex viscosity of these pretreated slurries show significant decreases with increasing biomass loading, $\sim 30 \times$ for a biomass loading of $10 \mathrm{wt} \%$ and $\sim 130 \times$ for a biomass loading of $50 \mathrm{wt} \%$. It is well known that mixing at high loadings is problematic and requires more power to efficiently stir highly viscous slurries. Our finding that shear thinning behavior is enhanced at high solids loading, leading to a reduction in complex viscosity by

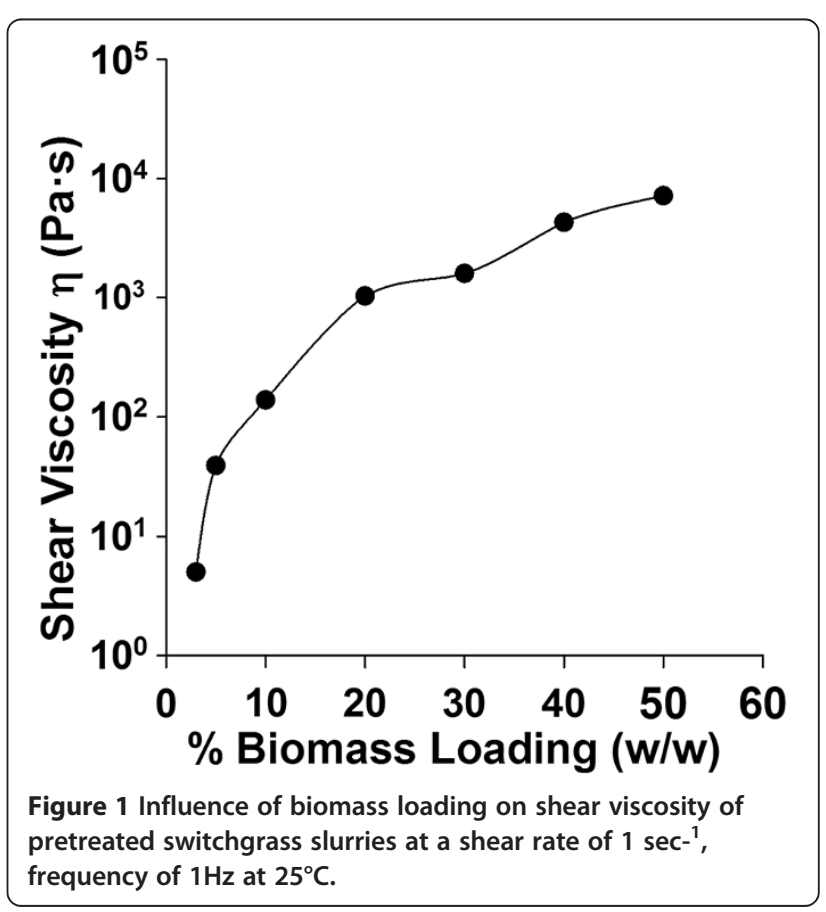




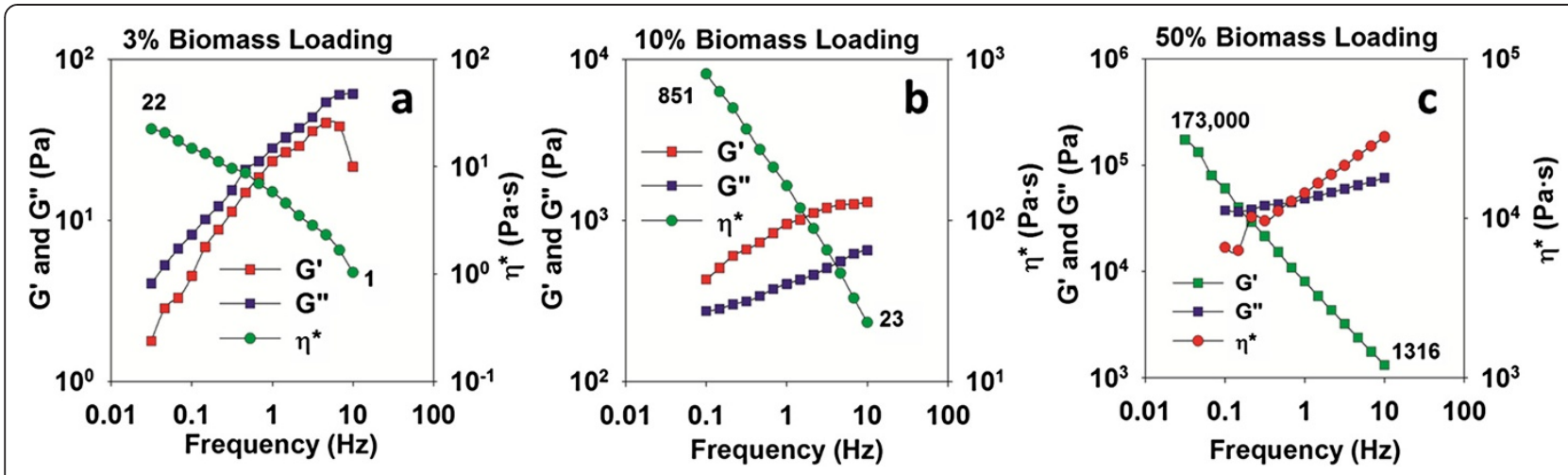

Figure 2 Storage modulus $\left(G^{\prime}\right)$, loss modulus $\left(G^{\prime \prime}\right)$ and complex viscosity $\left(\eta^{*}\right)$ of pretreated switchgrass slurries during frequency sweep from 0.01 to $10 \mathrm{~Hz}$ at biomass loading $\mathrm{s}$ of $3 \mathrm{wt} \%$ (a), $10 \mathrm{wt} \%$ (b) and $50 \mathrm{wt} \%$ (c).

two orders of magnitude, is therefore of great importance and could enable researchers to design reactors that induce shear stress and in turn achieve viscosity similar to lower loadings, allowing uniform heat transfer and mixing during pretreatment. While this does not completely offset the cost of the IL cost on a per $\mathrm{kg}$ basis, it does reduce the amount, and therefore the cost, of IL needed to pretreat biomass and develops energy-efficient methods by which to pretreat biomass.

Effect of biomass loading on the chemical composition of pretreated switchgrass

Effect of biomass loading on sugar composition of pretreated switchgrass

The sugar compositions of the untreated and pretreated recovered solids are shown in Figure 3. As expected, and as reported previously by Arora et al., the glucan content of the recovered solid is higher $(68 \%)$ after $\left[\mathrm{C}_{2} \mathrm{mim}\right]$ [OAc] pretreatment at $3 \mathrm{wt} \%$ biomass loading when compared to that of untreated switchgrass (35\%) [17]. The xylan content of switchgrass recovered after IL pretreatment at $3 \mathrm{wt} \%$ biomass loading is lower than that of untreated biomass, indicating that these constituents are solubilized during $\left[\mathrm{C}_{2} \mathrm{mim}\right][\mathrm{OAc}]$ pretreatment and not recovered upon anti-solvent addition. We observe that further increasing the biomass loading during $\left[\mathrm{C}_{2} \mathrm{mim}\right]$ [OAc] pretreatment resulted in a monotonic decrease of the relative glucan content in the recovered solids and an increase of the xylan and lignin content of the recovered biomass solids after pretreatment. The amount of solids recovered after pretreatment increased from 3 to $10 \mathrm{wt} \%$, but decreased above $30 \mathrm{wt} \%$ (Figure 3 and Additional file 1). Maximum glucose recovery of $\sim 100 \%$ (relative to the original biomass) was obtained in the solid recovered after pretreatment with 10 wt\% biomass loading (Additional file 1), but dropped significantly at higher levels. This observed trend of decreasing solid recoveries and increasing liquid recovery levels at higher loading levels is unexpected. We hypothesize that at these loading levels there are significant changes that occur during the addition of the anti-solvent that enhance the solubility of the glucan, but more work is needed to ascertain the exact mechanisms involved. Lignin removal efficiency was observed to decrease as the biomass loading is increased (Figure 3 and Additional file 1). Delignification during IL pretreatment has been shown to be due to the dissolution of lignin in IL [18]. The extent of delignification obtained at 3 and $30 \mathrm{wt} \%$ is comparable to that reported in the literature $[7,17,18]$. The extent of lignin dissolution in the IL decreases with increase in biomass loading. This lower dissolution leads to increased recovery of the lignin with the cellulose and hemicelluloses fraction in the recovered biomass after $\left[\mathrm{C}_{2} \mathrm{mim}\right][\mathrm{OAc}]$ pretreatment. It is interesting to note that the relative compositional profile of the polysaccharides and lignin in the recovered solids after pretreatment at $50 \mathrm{wt} \%$ is comparable to the initial switchgrass.

\section{Effect of biomass loading on saccharification efficiency}

All of the $\left[\mathrm{C}_{2} \mathrm{mim}\right][\mathrm{OAc}]$ pretreated switchgrass at all loading levels generated a material that was efficiently hydrolyzed using a commercial cellulase (CTec2) and hemicellulase (HTec2) cocktail from Novozymes, with total reducing sugar saccharification yields of more than $96 \%$ for all of the biomass loadings achieved within $24 \mathrm{~h}$ of hydrolysis (Figure 3 and 4a). The rate of total sugars released from recovered biomass was detected by 3,5-dinitrosalicylic acid (DNS) assay normalized to the starting biomass sugar concentration (Figure $4 \mathrm{~b}$ and Additional file 1: Figure S4), and the initial rate of glucose and xylose were measured by HPAEC (Figure 4c and Additional file 1: Figure S4) and show the impact of biomass loading on sugar yields and hydrolysis kinetics. The maximum observed total sugar recovery of $83.7 \%$ of total sugars from starting biomass resulting in the sugar recovery of $96 \%$ of glucose from starting biomass and $57 \%$ of the xylose from starting 


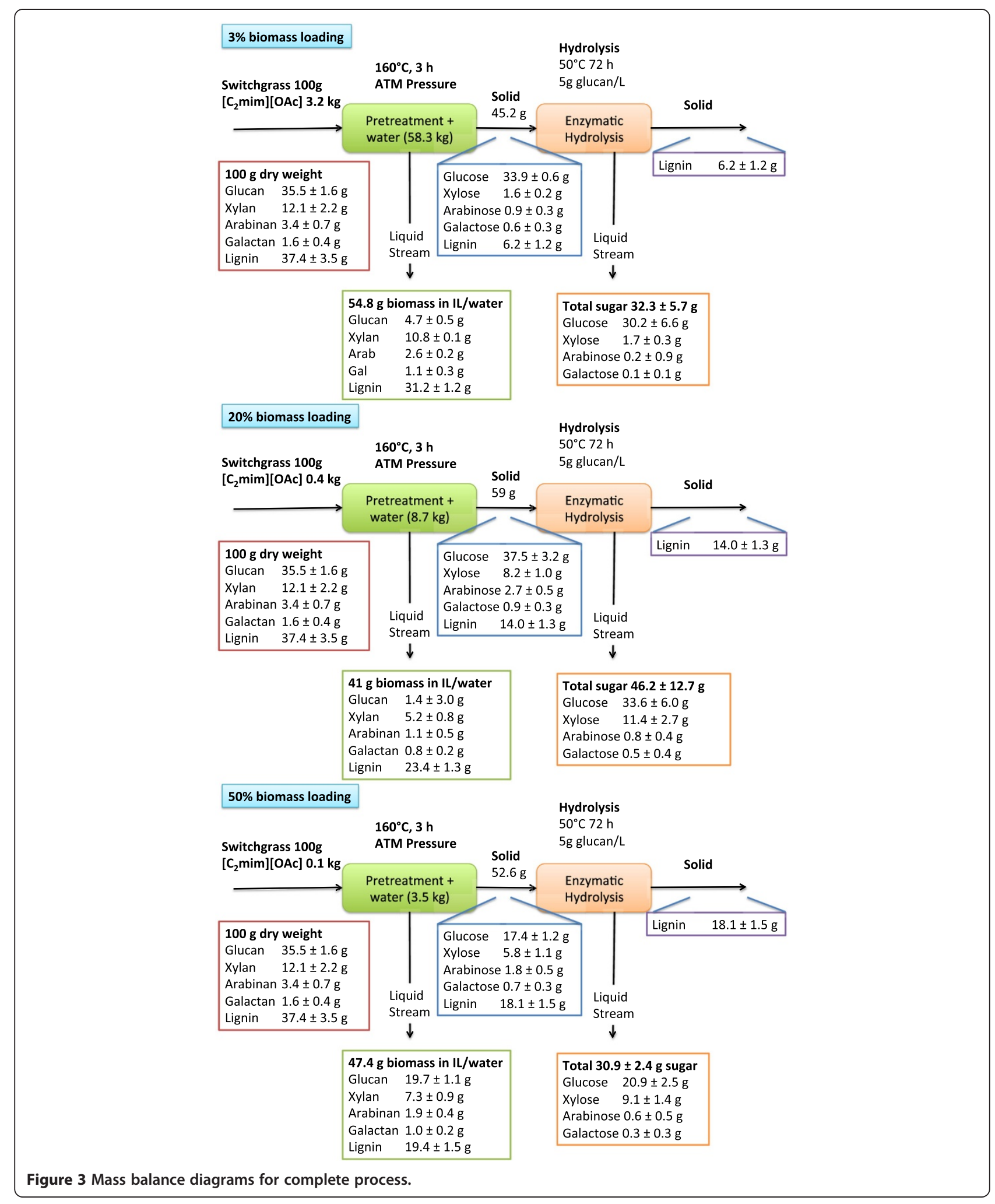




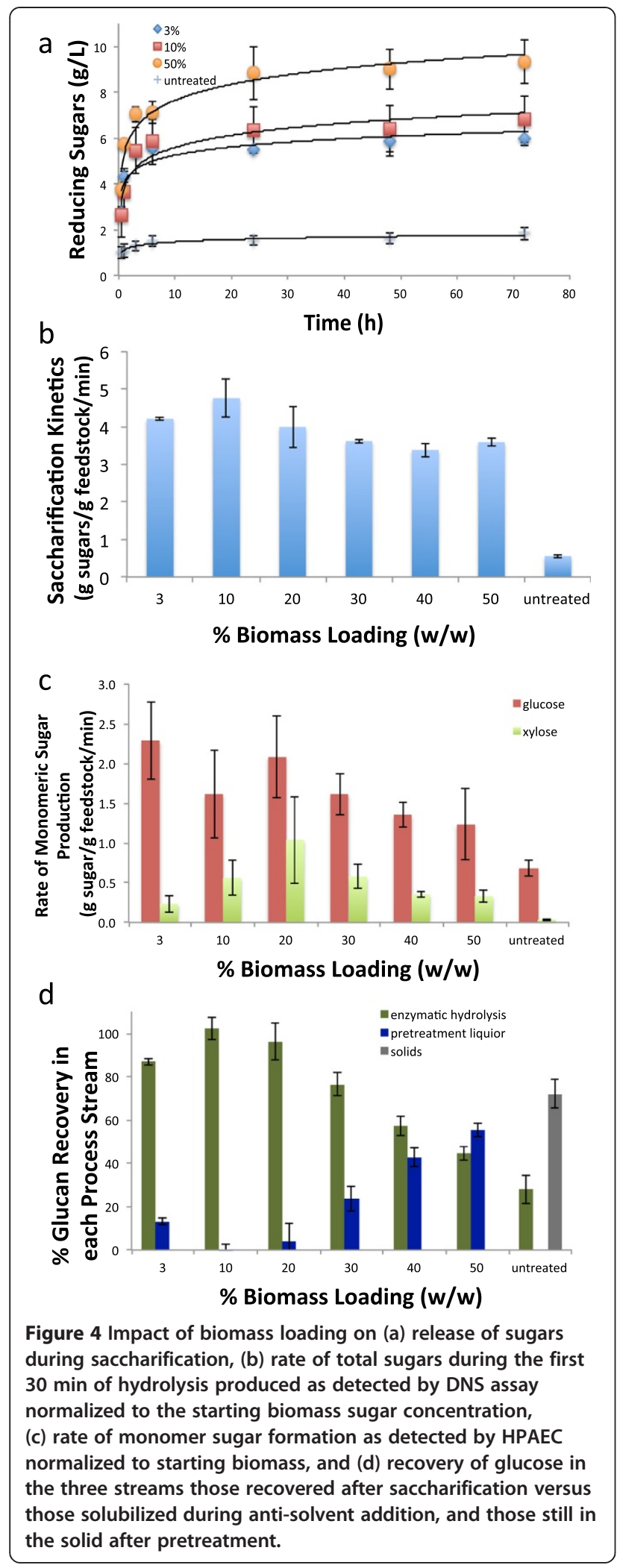

biomass was produced from the $20 \mathrm{wt} \%$ biomass loading pretreatment, and $45 \%$ solids recovery resulting in $64 \%$ of total sugar from starting biomass recovery for $3 \mathrm{wt} \%$ biomass loading. Analysis of the relative glucose present in the recovered solids, pretreatment liquor and final residual solid after saccharification process streams indicate that at all of the biomass loadings very little $(<1 \%)$ glucose remained as a solid (Figure 4d). The solids recovered after IL pretreatment at levels $>3 \mathrm{wt} \%$ resulted in a material with higher xylan content. Even though the hemicelluloses present in the biomass have been suggested to hinder the access of cellulases $[33,34]$ we observe a synergistic effect of the two enzyme cocktails, and the hydrolysis kinetics increase with increases in the xylose to glucose ratio [15].

Initial rate of enzymatic hydrolysis, as measured by DNS assay, for IL pretreated switchgrass was at least 5 times greater than that of untreated switchgrass ( $8 \mathrm{mg} / \mathrm{L} / \mathrm{min}$, Figure 4b, 4c Additional file 1: Figure S5). The rate of hydrolysis to glucose, as measured by HPAEC, remains constant at higher biomass loadings. The rate of hydrolysis to xylose, as measured by HPAEC, increases with biomass loading above $3 \mathrm{wt} \%$. As expected, the hydrolysis rate and the total amount of hydrolyzed sugar increases as the xylan content relative to the glucan content in the recovered solids increases (Additional file 1). These results are in agreement with the sugar composition of the pretreated biomass, which show that xylose content of the pretreated biomass increases with increase in biomass loading above $3 \mathrm{wt} \%$. Interestingly, although the composition of the biomass at $50 \%$ loading is similar to that of the untreated biomass, the saccharification rate is higher for the pretreated biomass with correspondingly higher sugar yields. Approximately all of the sugar was released from recovered biomass at $50 \%$ loading, but only $\sim 30 \%$ from of the untreated and demonstrates IL pretreatment with $\left[\mathrm{C}_{2} \mathrm{mim}\right]$ [OAc] to be efficient at high loadings due to significant changes to cellulose accessibility. In contrast, a recent study conducted on corn stover at similar loadings but milder pretreatment conditions show reduction in saccharification efficiency from the pretreated biomass at 50\% [7]. We attribute these differences due to the higher severity of the IL pretreatment process used in this report.

A complete mass balance following the amounts of IL, biomass, water used and amounts and composition of recovered solids and sugar yield in the different process streams for all the biomass loadings is presented in Figure $3(3,20,50 \mathrm{wt} \%)$ and Additional file 1: Figure S3. Similar to dilute acid and hot water pretreatments, the material solubilized during pretreatment and present in the pretreatment liquor and subsequent washes could be recovered and processed in additional unit operations and converted into fuels through fermentation. Furthermore, the high loading scenario could be useful with a wash-free consolidated 
pretreatment-saccharification process using recently developed IL-tolerant enzymes [35].

\section{Effect of biomass loading on the cellulose crystallinity of pretreated switchgrass}

XRD analysis was performed to better understand the high saccharification kinetics observed for pretreated switchgrass with high biomass loading. The powder XRD values of untreated and treated switchgrass samples are presented in Figure 5. As expected, there are three broad peaks at $16.1^{\circ}, 22.1^{\circ}$ and $35.0^{\circ}$ for untreated switchgrass that are consistent with known values of the cellulose I lattice structure $[18,30]$. After $\left[\mathrm{C}_{2} \mathrm{mim}\right][\mathrm{OAc}]$ pretreatment, the cellulose crystalline structure changed from cellulose I to II for switchgrass pretreated at $3 \mathrm{wt} \%$ loading, as indicated by the peaks at $11.6^{\circ}$ and $20.3^{\circ}[18,30]$. Although cellulose II polymorph is observed at lower biomass loadings, the peaks for cellulose II are undetectable at $50 \%$ biomass loading. The presence of cellulose II has been proven to be a result of the dissolution and regeneration process [30]. The calculated crystallinity index (CrI) of the pretreated switchgrass is observed to decrease from a value of 0.35 at 3 wt\% to a value of 0.17 at 30 wt\%. At 40 and $50 \mathrm{wt} \%$ loading, the pretreated switchgrass samples are almost completely amorphous with a CrI of 0.08 and 0.03 , respectively. We hypothesize that $\left[\mathrm{C}_{2} \mathrm{mim}\right][\mathrm{OAc}]$ was able to impact the cellulose I structure by swelling without extensive solubilization at these higher biomass loadings. As the cellulose fibers are not completely solubilized in $\left[\mathrm{C}_{2} \mathrm{mim}\right][\mathrm{OAc}]$, a transformation to cellulose II is not likely due to the restriction in the motion of cellulose chains in the plant cell wall. This is different from the prior study of $\left[\mathrm{C}_{2} \mathrm{mim}\right][\mathrm{OAc}]$ pretreated corn stover, where with increasing biomass loading, the effect of decrystallization

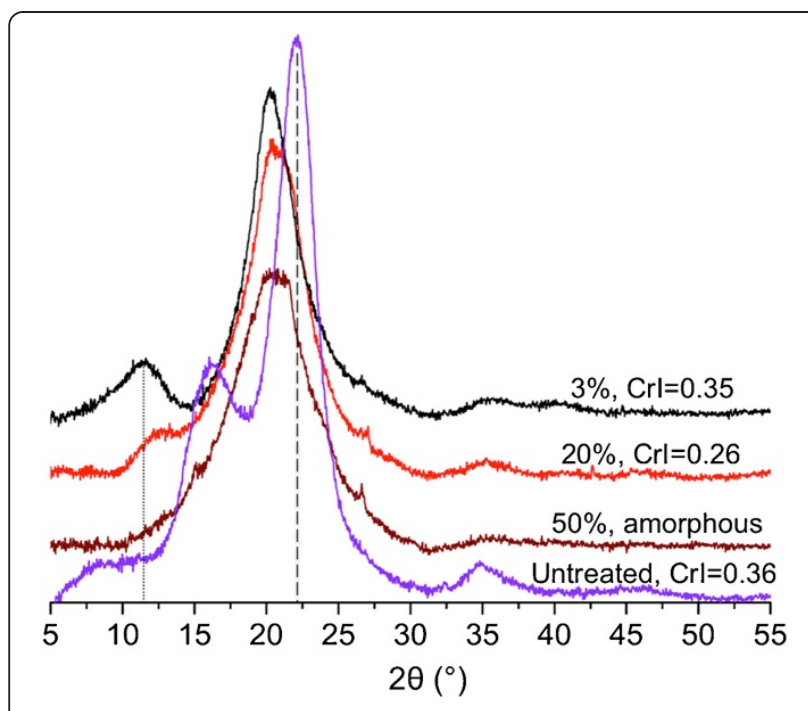

Figure 5 XRD analysis of initial switchgrass and as a function of biomass loading after pretreatment with $\left[\mathrm{C}_{2} \mathrm{mim}\right][\mathrm{OAc}]$. by $\left[\mathrm{C}_{2} \mathrm{mim}\right][\mathrm{OAc}]$ pretreatment decreased [7] and no cellulose II structure was reported. It is noted that in that study the pretreatment temperature was $120^{\circ} \mathrm{C}$ and time was $1 \mathrm{~h}$, which may explain the observed differences. The complete transformation of cellulose structure from crystalline to amorphous at 50\% loading provides an explanation on the observed similarities in biomass composition but different sugar yields and hydrolysis kinetics obtained from untreated switchgrass.

\section{Conclusions}

We have investigated the impact of high biomass loading on IL pretreatment of switchgrass using $\left[\mathrm{C}_{2} \mathrm{mim}\right][\mathrm{OAc}]$. The rheological properties during pretreatment are important for the evaluation, development, and design of large-scale process pretreatment processes. Pretreated slurries undergo a transition from behaving as a fluid to a solid-like when increasing the biomass loading from 3 to $10 \mathrm{wt} \%$. Though high biomass loading increases the viscosity, there is an increasing enhancement of shear thinning leading to a slurry with a lower complex viscosity at high loadings. Further, the kinetic rate decreases and total sugar recovery increases at this transition. Similar trends are observed between 10 and $50 \mathrm{wt} \%$ in terms of decreasing cellulose crystallinity, increasing viscosity, reduced delignification, and increasing hydrolysis rate kinetics. The shear thinning behavior observed at higher biomass loading levels impacts the design of the pumps, mixers and other equipment used in moving and mixing the pretreated slurries. The enhancement of total sugar recovery at 10 to $30 \mathrm{wt} \%$ biomass loading levels could reduce the costs of IL pretreatment. Furthermore, the increased biomass loadings result in increased recovery of hemicellulose and reduce the extraction of lignin into the IL that may enable the facile recovery and recycle of the IL. There is also a reduction in the amount of water per starting $\mathrm{kg}$ of biomass needed to wash the biomass at higher biomass loadings. An unanticipated benefit of increasing the loading levels to $40-50 \mathrm{wt} \%$ is the decrease of the cellulose crystallinity after $\left[\mathrm{C}_{2} \mathrm{mim}\right][\mathrm{OAc}]$ pretreatment that produced faster hydrolysis kinetics and may enable even lower enzyme loading levels that could improve the economic viability of IL pretreatment. These results indicate that design of reactors to induce shear stress leading to significantly lowered viscosity could improve mixing (mass and heat transfer) and allow IL pretreatments at higher loadings without compromising the benefits of high sugar yields obtained at low loadings and improve the overall economics of IL pretreatment process.

\section{Materials and methods}

\section{IL pretreatment}

1-ethyl-3-methylimidazolium acetate, abbreviated hereafter as $\left[\mathrm{C}_{2} \mathrm{mim}\right][\mathrm{OAc}]$, was purchased from BASF and used as 
the IL for all pretreatments in this study. Switchgrass was provided by Dr. Daniel Putnam, University of California at Davis. The switchgrass was milled and sieved through a 40 mesh (0.255-0.451 mm) sieve using a Wiley mill and stored at $4^{\circ} \mathrm{C}$ in a cold room before use. Switchgrass was pretreated with $\left[\mathrm{C}_{2} \mathrm{mim}\right][\mathrm{OAc}]$ at $160^{\circ} \mathrm{C}$ for $3 \mathrm{~h}$ using a previously published protocol [17,32]. Biomass loading in $\left[\mathrm{C}_{2} \mathrm{mim}\right][\mathrm{OAc}]$ was varied from $3,5,10,20,30,40$ and $50 \mathrm{wt} \%$. Aliquots of $0.6 \mathrm{ml}$ from the pretreated slurries were used for measuring rheological properties.

After pretreatment was completed, the samples were thoroughly mixed and hot water was added to the above samples at 3.5 times the initial total mass (of both biomass and IL) to recover any solubilized biomass. The mixture of IL, water, and biomass was centrifuged to separate the solid (biomass) and liquid $\left(\left[\mathrm{C}_{2} \mathrm{mim}\right][\mathrm{OAc}]\right.$ and water $)$ phases. The biomass was washed five times with hot water to remove any excess $\left[\mathrm{C}_{2} \mathrm{mim}\right][\mathrm{OAc}]$. The recovered solid was lyophilized (Labconco FreeZone ${ }^{(12)}$ ) and used for analysis.

\section{Rheology measurements}

A Malvern KinexusPro Rheometer was used to determine the rheological properties of $\left[\mathrm{C}_{2} \mathrm{mim}\right][\mathrm{OAc}]$ pretreated switchgrass slurries with different biomass loading $(3,5,10$, $20,30,40$ and 50 wt\%). A shear ramp was used to evaluate non-Newtonian behavior of the slurries. Oscillatory experiments were used to evaluate viscoelastic behavior at room temperature, and were conducted with the sample sandwiched between $25 \mathrm{~mm}$ serrated plate at a frequency of 0.01-10 Hz. The viscoelastic properties were also measure under different shear stress ranging from $0.1-40 \mathrm{~Pa}$ $[9,36,37]$. A $0.6 \mathrm{~mL}$ aliquot of the pretreated slurry was loaded onto the serrated $25 \mathrm{~mm}$ plate and the spindle was lowered to a gap value of 1 to $2 \mathrm{~mm}$ where force response was stabilized (Additional file 1: Figure S1) [38]. Plate temperature was controlled at $25^{\circ} \mathrm{C}$ using an integrated Peltier, and a plate cover was used to avoid evaporation of water from the samples during analysis.

\section{Compositional analysis \\ Total sugar analysis}

Structural carbohydrates (including cellulose, xylan, arabinan, and galactan) of switchgrass, before and after pretreatment, were determined according to the two-step acid hydrolysis procedure of the National Renewable Energy Laboratory (NREL) [39]. Carbohydrates were diluted 1000 fold and analyzed by HPAEC on an ICS-3000 system (Dionex, Sunnyvale, CA) equipped with an electrochemical detector and a $4 \times 250 \mathrm{~mm}$ CarboPac SA10 analytical column. Depending on the starting concentration, 1 or $10 \mu \mathrm{L}$ of the sample was injected into the column and eluted with $1 \mathrm{mM} \mathrm{KOH}$ for $14 \mathrm{~min}$. The flow rate of the eluent was maintained at $1 \mathrm{~mL} / \mathrm{min}$.

\section{Lignin analysis}

Total lignin content of the untreated and the pretreated switchgrass samples was measured by the acetyl bromide method $[17,40,41]$. All the reagents used in this method were purchased from Alfa Aesar. $5 \mathrm{mg}$ of biomass was added to $0.2 \mathrm{ml}$ of $25 \%$ (w/w) acetyl bromide in glacial acetic acid. The tubes were sealed and incubated for $3 \mathrm{~h}$ in a thermomixer operated at $50^{\circ} \mathrm{C}$ and $900 \mathrm{rpm}$. The samples were cooled to room temperature over ice and then centrifuged at $10,000 \mathrm{rpm}$ for $5 \mathrm{~min}$. $0.1 \mathrm{~mL}$ of the sample was transferred to a new Eppendorf tube and, $0.4 \mathrm{~mL}$ of sodium hydroxide $(2 \mathrm{M})$ and $70 \mu \mathrm{L}$ of hydroxylamine hydrochloride $(0.5 \mathrm{M})$ were added. The solution was thoroughly mixed and $57 \mu \mathrm{L}$ of the sample was transferred to a 96 well plate and the final volume of the solution was made to $200 \mu \mathrm{L}$ with glacial acetic acid. A blank sample was also prepared using similar method (except the addition of biomass). The lignin content of the samples was calculated based on the absorbance at $280 \mathrm{~nm}$ using a UV spectrometer (Molecular devices, Spectra Max, model-M2) and mass extinction coefficient of 17.75 (switchgrass) was used in the calculation [40].

\section{Enzymatic saccharification}

Enzymatic saccharification of pretreated and untreated switchgrass samples was carried out at $50^{\circ} \mathrm{C}$ and $150 \mathrm{rpm}$ in a reciprocating shaker. Hydrolysis reactions were carried out in $50 \mathrm{mM}$ sodium acetate buffer ( $\mathrm{pH}$ of 4.8 ). The glucan content in the solution was maintained at 5 g glucan per liter. $20 \mathrm{mg}$ protein/ g glucan of Cellic CTec2 (Novozymes) and $2 \mathrm{mg}$ protein/g xylan of Cellic HTec2 (Novozymes) were used for hydrolysis reactions. $60 \mu \mathrm{L}$ of the supernatant was taken at specific time intervals $(0,0.5,1,3,6,24,48$ and $72 \mathrm{~h})$ to monitor hydrolysis kinetics. The supernatants were centrifuged at 10,000 g for $5 \mathrm{~min}$, and the reducing sugars in the supernatant were measured using the DNS assay. Solutions of D-glucose were used as standards in the DNS assay. The untreated switchgrass controls were run concurrently with all recovered samples to eliminate potential differences in temperature history or other parameters. The rate of hydrolysis was calculated based on the sugar released in the first $30 \mathrm{~min}$ of hydrolysis [32]. The supernatant collected after $72 \mathrm{~h}$ of hydrolysis was analyzed with high-pressure anion exchange chromatography (HPAEC) for the monosaccharide composition. All assays were performed in triplicates. It should be noted that the DNS assay does not account for the hydrolysis reaction stoichiometry, $1 \mathrm{~g}$ of cellulose and $1 \mathrm{~g}$ of hemicellulose upon complete hydrolysis produce $1.11 \mathrm{~g}$ glucose and $1.12 \mathrm{~g}$ xylose [32].

\section{X-ray powder diffraction measurements}

Powder X-ray diffraction (XRD) patterns of biomass samples were obtained using a PANalytical Empyrean 
diffractometer equipped with a PIXcel ${ }^{3 \mathrm{D}}$ detector operated in 1D scanning mode. Samples from three replicates were mixed for XRD analysis. Scans were collected at $45 \mathrm{kV}$ and $40 \mathrm{~mA}$ with a wavelength of $1.5418 \AA$ (CuKa radiation). A reflection-transmission spinner was used as a sample holder and the spinning rate was set at $4 \mathrm{rpm}$. The patterns were collected in the $2 \theta$ range of 5 to $55^{\circ}$, the step size was $0.026^{\circ}$, and the exposure time was 300 seconds. The crystallinity index was determined by a curve fitting procedure of the measured diffraction patterns using the HighScore Plus ${ }^{\circledR}$ software package.

\section{Additional file}

Additional file 1: Figure S1. Rheology Measurements of pretreated slurry between $25 \mathrm{~mm}$ plates with $3 \%$ biomass loading (a) and (b), and with $50 \%$ biomass loading (c). Figure S2. Storage modulus, loss modulus and shear viscosity of pretreated switchgrass slurries during frequency sweep from 0.01 to $10 \mathrm{~Hz}$ with biomass loading of 20\% (a), 30\% (b), 40\% (c). Figure S3. Mass Balance for 10\%, 30\% and 40\% biomass loadings. Figure S4. Impact of biomass loading on saccharification kinetics and reducing sugar (a) saccharification kinetics, (b) rate of total sugars produced as detected by DNS assay, (c) recovery of sugars taking into account the saccharification sugar release and solid recovery from IL pretreatment, (e) rate of monomer sugar formation as detected by HPAEC, and, (g) recovery of sugars after enzymatic hydrolysis compared to initial biomass.

\section{Abbreviations}

IL: Ionic Liquid; Crl: Crystallinity index; [ $\mathrm{C}_{2}$ mim][OAc]: 1-ethyl-3methylimidazolium acetate.

\section{Competing interests}

The strategy described in this paper has been included in a patent application.

\section{Authors' contributions}

SS designed and coordinated the study; AC, PV, CS, CM, GC, DZ, BAS and SS conducted the experiments and data analysis. JM, SS, YC and AC conducted viscosity experiments. VS and GC conducted XRD analysis. AC, PV, CS, GC, BAS and SS wrote the manuscript. All authors read and approved the final manuscript.

\section{Acknowledgments}

This work was part of the DOE Joint BioEnergy Institute (http://www.jbei.org) supported by the US Department of Energy, Office of Science, Office of Biological and Environmental Research, through contract DE-AC02-05CH11231 between Lawrence Berkeley National Laboratory and the US Department of Energy. The Advanced Light Source is supported by the Director, Office of Science, Office of Basic Energy Sciences, of the U.S. Department of Energy under Contract No. DE-AC02-05CH11231. We would also like to thank the Laboratory of Dr. Daniel Putnam from the University of California at Davis for providing the switchgrass. The authors thank Novozymes for the gift of the enzyme cocktails used in this work and to Patanjali Varanasi for lignin analysis.

\section{Author details}

${ }^{1}$ Deconstruction Division, Joint BioEnergy Institute, Lawrence Berkeley National Laboratory, Berkeley CA, USA. ${ }^{2}$ Biological and Materials Science Center, Sandia National Laboratories, Livermore CA, USA. ${ }^{3}$ Beijing University of Chemical Technology, Beijing, China. ${ }^{4}$ Malvern Instruments LTD, Worcestershire WR14 1XZ, UK. ${ }^{5}$ Advanced Light Source, Lawrence Berkeley National Laboratory, Berkeley, CA, USA.

Received: 12 October 2012 Accepted: 27 February 2013 Published: 11 April 2013

\section{References}

1. Binder JB, Raines RT: Fermentable sugars by chemical hydrolysis of biomass. P Natl Acad Sci USA 2010, 107:4516-4521.

2. McMillan JD: Pretreatment of lignocellulosic biomass. Enzymatic Conversion Biomass Fuels Prod 1994, 566:292-324.

3. Banerjee S, Mudliar S, Sen R, Giri B, Satpute D, Chakrabarti T, Pandey RA: Commercializing lignocellulosic bioethanol: technology bottlenecks and possible remedies. Biofuel Bioprod Bior 2010, 4:77-93.

4. Zhu L, O'Dwyer JP, Chang VS, Granda CB, Holtzapple MT: Structural features affecting biomass enzymatic digestibility. Bioresource Technol 2008, 99:3817-3828.

5. Klein-Marcuschamer D, Simmons BA, Blanch HW: Techno-economic analysis of a lignocellulosic ethanol biorefinery with ionic liquid pre-treatment. Biofuel Bioprod Bior 2011, 5:562-569.

6. Sen SM, Binder JB, Raines RT, Maravelias CT: Conversion of biomass to sugars via ionic liquid hydrolysis: process synthesis and economic evaluation. Biofuel Bioprod Bior 2012, 6:444-452.

7. Wu H, Mora-Pale M, Miao JJ, Doherty TV, Linhardt RJ, Dordick JS: Facile Pretreatment of lignocellulosic biomass at high loadings in room temperature lonic liquids. Biotechnol Bioeng 2011, 108:2865-2875.

8. Palmqvist $B$ et al: Effect of mixing on enzymatic hydrolysis of steampretreated spruce: a quantitative analysis of conversion and power consumption. Biotechnology for Biofuels 2011, 4:10.

9. Stickel JJ, Knutsen JS, Liberatore MW, Luu W, Bousfield DW, Klingenberg DJ, Scott CT, Root TW, Ehrhardt MR, Monz TO: Rheology measurements of a biomass slurry: an inter-laboratory study. Rheol Acta 2009, 48:1005-1015.

10. Dunaway KW, Dasari RK, Bennett NG, Berson RE: Characterization of changes in viscosity and insoluble solids content during enzymatic saccharification of pretreated corn stover slurries. Bioresource Technol 2010, 101:3575-3582.

11. Pimenova NV, Hanley AR: Effect of corn stover concentration on rheological characteristics. App/ Biochem Biotech 2004, 113:347-360

12. Pimenova NV, Hanley TR: Measurement of rheological properties of corn stover suspensions. Appl Biochem Biotech 2003, 105:383-392.

13. Viamajala S, McMillan JD, Schell DJ, Elander RT: Rheology of corn stover slurries at high solids concentrations - Effects of saccharification and particle size. Bioresource Technol 2009, 100:925-934.

14. Wiman M, Palmqvist B, Tornberg E, Liden G: Rheological characterization of dilute acid pretreated softwood. Biotechnol Bioeng 2011, 108:1031-1041.

15. Li CL, Cheng G, Balan V, Kent MS, Ong M, Chundawat SPS, Sousa LD, Melnichenko YB, Dale BE, Simmons BA, Singh S: Influence of physico-chemical changes on enzymatic digestibility of ionic liquid and AFEX pretreated corn stover. Bioresour Technol 2011, 102:6928-6936.

16. Stone JE, Scallan AM, Donefer E, Ahlgren E: Digestibility as a simple function of a molecule of similar size to a cellulase enzyme. Adv Chem Ser 1969:219.

17. Arora R, Manisseri C, Li CL, Ong MD, Scheller HV, Vogel K, Simmons BA, Singh $\mathrm{S}$ : Monitoring and analyzing process streams towards understanding lonic liquid pretreatment of switchgrass (Panicum virgatum L.). Bioenerg Res 2010, 3:134-145.

18. Singh S, Simmons BA, Vogel KP: Visualization of biomass solubilization and cellulose regeneration during lonic liquid pretreatment of switchgrass. Biotechnol Bioeng 2009, 104:68-75.

19. Ehrhardt MR, Monz TO, Root TW, Connelly RK, Scott CT, Klingenberg DJ: Rheology of dilute acid hydrolyzed corn stover at high solids concentration. Appl Biochem Biotech 2010, 160:1102-1115.

20. Han YW, Lee JS, Anderson AW: Chemical composition and digestibility of ryegrass straw. J Agr Food Chem 1975, 23:928-931.

21. Grohmann $K$, Torget $R$, Himmel M: Dilute acid pretreatment of biomass at high solids concentrations. Aspen Bibliography 1986, 467

22. Huang RL, Su RX, Qi W, He ZM: Understanding the key factors for enzymatic conversion of pretreated lignocellulose by partial least square analysis. Biotechnol Progr 2010, 26:384-392.

23. Chen F, Dixon RA: Lignin modification improves fermentable sugar yields for biofuel production. Nat Biotechnol 2007, 25:759-761.

24. Converse AO, Ooshima H, Burns DS: Kinetics of enzymatic-hydrolysis of lignocellulosic materials based on surface-area of cellulose accessible to enzyme and enzyme adsorption on lignin and cellulose. Appl Biochem Biotech 1990, 24-5:67-73. 
25. Bak JS, Ko JK, Han YH, Lee BC, Choi IG, Kim KH: Improved enzymatic hydrolysis yield of rice straw using electron beam irradiation pretreatment. Bioresource Technol 2009, 100:1285-1290.

26. Agarwal UP, Zhu JY, Ralph SA: Enzymatic hydrolysis of biomass: effects of crystallinity, particle size, and lignin removal. In 6th international symposium on wood, fiber and pulping chemistry. Tianjin, China: China Light Industry Press; 2011:910-914.

27. Jeoh T, Ishizawa Cl, Davis MF, Himmel ME, Adney WS, Johnson DK: Cellulase digestibility of pretreated biomass is limited by cellulose accessibility. Biotechnol Bioeng 2007, 98:112-122.

28. Chang VS, Holtzapple MT: Fundamental factors affecting biomass enzymatic reactivity. Appl Biochem Biotech 2000, 84-6:5-37.

29. Laureano-Perez L, Teymouri F, Alizadeh H, Dale BE: Understanding factors that limit enzymatic hydrolysis of biomass. Appl Biochem Biotech 2005, 121:1081-1099.

30. Cheng G, Varanasi P, Li CL, Liu HB, Menichenko YB, Simmons BA, Kent MS, Singh S: Transition of cellulose crystalline structure and surface morphology of biomass as a function of lonic liquid pretreatment and its relation to enzymatic hydrolysis. Biomacromolecules 2011, 12:933-941.

31. Dadi AP, Schall CA, Varanasi S: Mitigation of cellulose recalcitrance to enzymatic hydrolysis by lonic liquid pretreatment. Appl Biochem Biotech 2007, 137:407-421.

32. Li CL, Knierim B, Manisseri C, Arora R, Scheller HV, Auer M, Vogel KP, Simmons BA, Singh S: Comparison of dilute acid and ionic liquid pretreatment of switchgrass: Biomass recalcitrance, delignification and enzymatic saccharification. Bioresour Technol 2010, 101:4900-4906.

33. Samayam IP, Schall CA: Saccharification of ionic liquid pretreated biomass with commercial enzyme mixtures. Bioresource Technol 2010, 101:3561-3566.

34. Selig C, Wolf M, Muller T, Dandekar T, Schultz J: The ITS2 database II: homology modelling RNA structure for molecular systematics. Nucleic Acids Res 2008, 36:D377-D380.

35. Park JI, Steen EJ, Burd H, Evans SS, Redding-Johnson AM, Batth T, Benke PI, D'haeseleer P, Sun N, Sale KL, et al: A thermophilic lonic liquid-tolerant cellulase cocktail for the production of cellulosic biofuels. PLOS ONE 2012, 7(5):e37010.

36. Walls HJ, Caines SB, Sanchez AM, Khan SA: Yield stress and wall slip phenomena in colloidal silica gels. J Rheol 2003, 47:847-868.

37. Yang MC, Scriven LE, Macosko CW: Some rheological measurements on magnetic iron-oxide suspensions in silicone oil. J Rheol 1986, 30:1015-1029

38. Knutsen JS, Liberatore MW: Rheology of high-solids biomass slurries for biorefinery applications. J Rheol 2009, 53:877-892.

39. Sluiter A: Determination of structural carbohydrates and lignin in biomass [electronic resource]: laboratory analytical procedure (LAP): issue date, 4/25/2008 / A. Sluiter et al. Golden, Colo: National Renewable Energy Laboratory; 2008.

40. Pandey KK, Pitman AJ: Examination of the lignin content in a softwood and a hardwood decayed by a brown-rot fungus with the acetyl bromide method and Fourier transform infrared spectroscopy. J Polym Sci Pol Chem 2004, 42:2340-2346.

41. Liyama K, Wallis AFA: An improved acetyl bromide procedure for determining lignin in woods and wood pulps. Wood Sci Technol 1988, 22:271-280.

doi:10.1186/1754-6834-6-52

Cite this article as: Cruz et al: Impact of high biomass loading on ionic liquid pretreatment. Biotechnology for Biofuels 2013 6:52.

\section{Submit your next manuscript to BioMed Central and take full advantage of:}

- Convenient online submission

- Thorough peer review

- No space constraints or color figure charges

- Immediate publication on acceptance

- Inclusion in PubMed, CAS, Scopus and Google Scholar

- Research which is freely available for redistribution

Submit your manuscript at www.biomedcentral.com/submit
C Biomed Central 